\title{
Factors Associated with Risky Sexual Behavior among Unmarried Most-at-Risk Young People in Cambodia
}

\author{
Siyan $\mathrm{Yi}^{1,2, *}$, Sovannary Tuot ${ }^{1}$, Kunthearith Yung ${ }^{3}$, Sanh $\mathrm{Kim}^{3}$, Chhorvann Chhea ${ }^{4}$, Vonthanak Saphonn ${ }^{5}$ \\ ${ }^{1}$ Research Department, KHANA, Cambodia \\ ${ }^{2}$ Public Health Program, College of Education and Health Sciences, Touro University, California, USA \\ ${ }^{3}$ Department of School Health, Ministry of Education, Youth, and Sports, Cambodia \\ ${ }^{4}$ School of Public Health, National Institute of Public Health, Cambodia \\ ${ }^{5}$ The University of Health Sciences, Cambodia \\ *Corresponding author: siyan@doctor.com
}

Received October 23, 2014; Revised November 05, 2014; Accepted November 09, 2014

\begin{abstract}
Background: Recent surveys suggest that adolescents and young adults in Southeast Asian nations are at great risks of sexual reproductive health issues. This study explored factors associated with risky sexual behavior (RSB) among unmarried most-at-risk young people in Cambodia. Methods: A two-stage cluster sampling method was used to select 1,204 boys and 1,166 girls aged 10-24 from 252 hotspots in the capital city and seven provinces. A five-item scale was constructed to measure RSB. All variables were entered simultaneously in multivariate logistic regression models if they were significantly associated with RSB in bivariate analyses. Results: Of total, $37.7 \%$ of boys and $18.5 \%$ of girls had sexual intercourse in the past three months; of them, $69.6 \%$ of boys and $52.5 \%$ of girls were involved in commercial sex. Only $43.3 \%$ of boys and $6.5 \%$ of girls reported always using condom with unpaid regular partners in the past three months. Among sexually active girls, $43.5 \%$ reported having been pregnant and of them, $42.4 \%$ reported having induced abortion as a result of their most recent pregnancy. After adjustment, boys with higher levels of RSB were significantly more likely to live in an urban area, to have completed $\geq 9$ years of formal education, and to be not currently living with parents. In contrast, girls with higher levels of RSB were significantly less likely to have completed $\geq 9$ years of formal education and to have both parents alive. Both boys and girls with higher levels of RSB were significantly more likely to be in the age group of 20-24, to be not currently in school, to be employed, to becurrent alcohol drinkers, to becurrent heavy alcohol drinkers, to be current illicit drug users, and to have been tested for HIV. Conclusions: Unmarried young people in this study are exposed to several sexual reproductive health problems such as HIV and sexually transmitted infections, unwanted pregnancy, and unsafe abortion. These findings suggest the need for research and prevention programs for these key populations taking into account risk factors identified in this study.
\end{abstract}

Keywords: most-at-risk young people, risky sexual behavior, risk factors, HIV/AIDS, sexual reproductive health, Cambodia

Cite This Article: Siyan Yi, Sovannary Tuot, Kunthearith Yung, Sanh Kim, Chhorvann Chhea, and Vonthanak Saphonn, "Factors Associated with Risky Sexual Behavior among Unmarried Most-at-Risk Young People in Cambodia." American Journal of Public Health Research, vol. 2, no. 5 (2014): 211-220. doi: 10.12691/ajphr-2-5-5.

\section{Introduction}

Adolescents and young adults, particularly young women, have been identified as the most vulnerable group in sexual reproductive health issues. In 2009, young people aged 15-24 accounted for approximately $40 \%$ of all new HIV infections worldwide [1], and 2.1 million adolescents aged 10-19 were estimated to be living with HIV in low- and middle-income countries [2]. Despite this alarming situation, only a few studies have been conducted to explore factors associated with sexual reproductive health behavior among young people in the resource-limited countries. Most recent surveys in Southeast Asian nations, including Cambodia, and anecdotal reports suggest that risky sexual behavior (RSB) among adolescents and young adults in these countries are very common [3-7].

Cambodia has one of the most youthful populations in Southeast Asia with approximately $32 \%$ of the total population between the ages of 10 and 24 [8]. Regarding HIV, Cambodia is among the few countries in the world to reverse the spread of HIV epidemic and has received a Millennium Development Goals award from the United Nations as a global recognition of the efforts to reduce HIV prevalence and achieve the universal access to antiretroviral therapy [2]. However, challenges remain to eliminating new HIV and other sexually transmitted infections (STIs), which are currently concentrated in key populations such as female entertainment workers, men who have sex with men, transgender individuals, and drug 
users [2]. Most of people in these high-risk groups are under the age of 24 [9].

Various socio-economic factors may expose young people to sexual reproductive health problems; among these factors, gender is the most important one. In our previous study among adolescent students in Cambodia, boys were significantly more likely to engage in RSB compared to girls [7]. Similar findings have also been reported in studies in other countries including the United States, China, Myanmar, and several other developing countries [5,10,11,12]. Boys are also more likely to have the first sexual intercourse at younger age and to have premarital sexual intercourse than girls [7,11,13]. However, girls are more vulnerable to the hardship and changes in socio-economic conditions and more likely to be coerced into sexual debut and exploitation than boys $[14,15]$.

A survey in Cambodia highlighted that out-of-school adolescents and young adults tend to engage in more RSB than those attending school [16]. In China, unmarried migrant young people were found to be exposed to premarital sex, and most of them lack knowledge and skills to avoid sexual reproductive health risks [17]. Moreover, they are naive to city life and unlikely to access to appropriate sexual reproductive health information and services $[18,19]$. In Cambodia, it is common that young people from poor, rural families migrate to cities in order to seek for job opportunities. Many migrant women enter into some form of transactional sexual relationship to augment their meager wages so they can sustain their lives in the cities and fulfill their obligations to send money home [20]. In turn, unmarried young people having an early sexual debut are at great risk of HIV and STIs, unwanted pregnancy, and unsafe abortion [21]. Other social factors associated with RSB among adolescents and young adults include substance use [7,22], peer affiliation [7,23,24], parental monitoring [25], parental trust [26], family relationship [27], family structure [28], and school engagement [23].

The critical issues of sexual reproductive health among this young population, together with the need for evidence in order to design relevant programs set the backdrop for research addressing multiple RSB and risk settings among Cambodian young people. We, therefore, conducted this study to explore risk factors associated with RSB among unmarried most-at-risk young people aged 10-24 in Cambodia. RSB is commonly defined as behavior that increases one's risk of contracting HIV and STIsor experiencing unintended pregnancies [30]. Findings from this study will serve as basic indicators of sexual reproductive health practices and associated characteristics among this key population, which will be useful for future research, development of school curriculum for adolescents, and designing intervention programs.

\section{Materials and Methods}

\subsection{Study Sites}

This cross-sectional study was conducted in February 2010 in Phnom Penh, the capital city and seven provinces including Battambang, Banteay Mean Chey, Kampong
Cham, Siem Reap, Preah Sihanouk, Koh Kong, and SvayRieng. These provinces were identified as priority sites for the study based on several criteria: (1) high number of female entertainment workers (e.g., girls working in entertainment establishments such as karaoke parlors, bars, restaurants, massage parlors, night clubs, beer gardens, etc.); (2) high HIV prevalence among female entertainment workers; (3) major tourist destinations; (4) high number of youth hostels and guesthouses; (5) high number of human trafficking victims; (6) high number of rape cases; (7) border areas; and (8) high number of men who have sex with men. In these selected sites, hotspots were identified and listed for the survey.

\subsection{Study Population and Sampling}

Young people in this study included entertainment workers, men who have sex with men, drug users, out-ofschool youths, and students. Representatives from these groups were involved as advisors in the study design, field work, consultations, and dissemination of the findings. To be included in this study, a person must: (1) be in the age group of 10-24; (2) present in the selected hotspots; and (3) agree to participate in the interview. 'Hotspots' were defined as locations where young people were known to congregate, involve in health risk behavior such as alcohol drinking and drug use, or meet new sexual partners. Using this definition, hotspots included bars, night clubs, karaoke parlors, massage parlors, street corners, places where youth frequently gather (football field, skating field...), public parks, snooker clubs, and computer game shops. Since the survey populations were not associated with a site, a time-location sampling method which is suitable for floating populations was used.

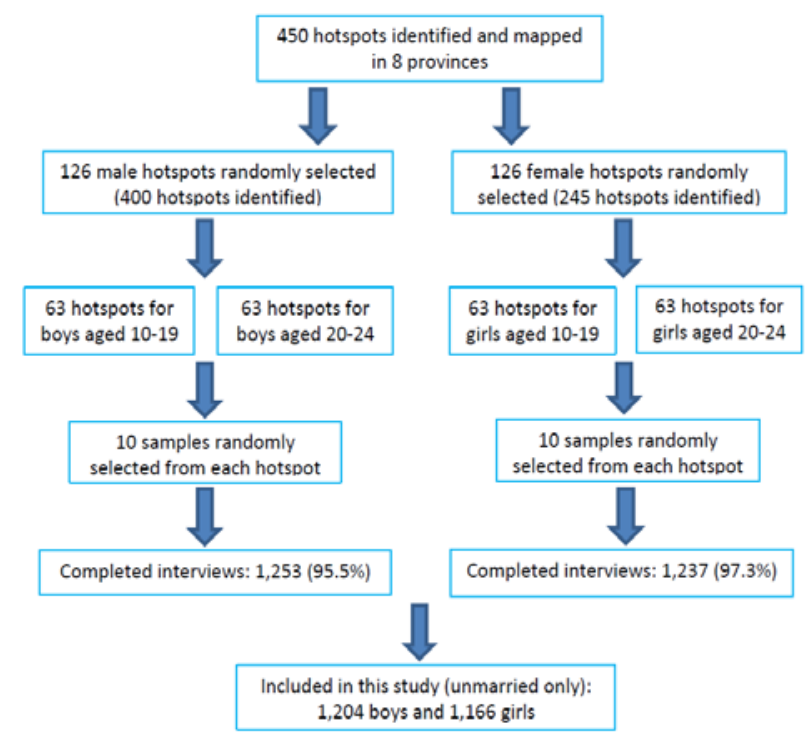

Figure 1. Sampling procedure

Sample size was calculated based on the expected prevalence of several variables to be measured in this study. Findings from the National Youth Behavior Survey 2004 [16] were used as a proxy for the expected prevalence in this estimation. Assuming that the lowest estimated prevalence of RSB the survey sought to estimate was $5 \%$ with a $2.2 \%$ margin of error, a $5 \%$ significance level and a design effect of 1.5 , the sample size required 
for each male and female group was 1,260 taking into account $12 \%$ refusal rate.

Figure 1 shows the sampling procedure of the study. In total, 450 hotspots in the selected city and provinces were identified, mapped, and listed by the research teams. A two-stage cluster sampling method was used to select the study samples. The first stage involved the random selection of 252 hotspots from the list (126 hotspots for boys and 126 hotspots for girls). Out of these 126 hotspots, 63 hotspots were selected for the age group of 10-19 and 63 hotspots for the age group of 20-24 in order to enable a deeper analysis of RSB in different age groups. At the second stage, 10 samples were randomly selected from each hotspot for interviews. In total, interviews were completed with 1,253 boys and 1,237 girls, yielding a response rate of $95.5 \%$ and $97.3 \%$ among boys and girls, respectively. In this study, we included only unmarried participants in the analyses.

\subsection{Training and Data Collection Procedure}

A four-day training was conducted for all interviewers and data collection supervisors. The training contents included a review on the study protocol and questionnaires, field practices, sampling techniques, consent forms, and preparation of the survey documents. Data were collected through interviews by two male and two female data collection teams. Each team composed of five members including a team leader and four interviewers. Survey coordinators and principal investigators regularly conducted field supervision.

\subsection{Questionnaire Development Measurements}

The questionnaires were developed separately for boys and girls. We initially developed the survey questionnaire in English and then translated it into Khmer, the national language of Cambodia. Another translator back-translated it into English to ensure that the "content and spirit" of every original item were maintained. Clear instructions and explanations were addressed to avoid any confusion during the interviews. We adapted several items that have been used widely in previous studies in Cambodia $[7,8,9,16,29]$.

\subsubsection{Socio-demographic Characteristics, Health Behavior, and HIV Testing}

Socio-demographic characteristics included age, residential area, years of formal education completed, current schooling status, current main occupation, and family living situations including questions on whether the respondents were living with parents and whether they had both parents alive. Age was grouped into two categories $(0=10-19,1=20-24)$, and years of education was also dichotomized using mean value of nine years as a cutoff $(0<9$ years, $1 \geq 9$ years). We also used yes/no questions to collect information on substance use including alcohol and illicit drug use and their perception regarding the level of their alcohol consumption. Respondents would be considered as 'current alcohol drinkers' or 'current illicit drug users' if they responded 'yes' to the questions asking whether they have drunk a full glass of any kind of alcohol or used any kind of illicit drugs in the past three months. Respondents were regarded as 'heavy drinkers' if they responded 'yes' to a question asking if they considered themselves as a 'heavy drinker.' Regarding HIV-related information, we asked whether they had been tested for $\operatorname{HIV}(0=$ no, $1=$ yes), place where the most recent HIV test was performed and whether they received the result of the most recent test $(0=$ no, $1=$ yes $)$. We also asked whether they had received HIV education $(0=$ no, $1=$ yes) and the sources of the information they received in the past three months.

\subsubsection{Sexual Behavior}

Several items were adapted to measure sexual behavior. To construct RSB scale, five items were selected including: (1) age at the first instance of sexual intercourse, (2) number of sexual partners in the past three months, (3) buying or selling sex in the past three months, (4) not always using condom when having sexual intercourse with 'unpaid regular partners' in the past three months, and (5) not always using condom when having sexual intercourse with commercial partners in the past three months. In this study, 'sexual intercourse' included vaginal and anal sex, but not oral sex. 'Commercial sex partner' refers to a partner with whom the respondents may have sexual intercourse in exchange for money or gifts, while 'unpaid regular partners' refers to a partner with whom respondents may have sexual intercourse not in exchange for money or gifts.

For age at the first instance of sexual intercourse, responses were coded as follows: 0 if the respondents never had sexual intercourse, 1 if the age reported was 18 or older, and 2 if the age reported was younger than 18 . Similarly, number of sexual partners in the past three months was coded as 0 if the respondents never had sexual intercourse or did not have sexual intercourse in the past three months, 1 if the number reported was one, and 2 if the number reported was two or more. For other variables, responses were coded as 0 if the participants never had sexual intercourse or did not have sexual intercourse with the specified partners in the past three months, 1 if the answer was 'no,' and 2 if the answer was 'yes.' The total score of the five measures was calculated, ranging from 0 to 10 with higher score indicating higher levels of RSB.

\subsection{Data Analyses}

Double data entry was performed using Epi Data. All data were analyzed separately for boys and girls to address gender differences. The study samples were divided into two groups using median value of the total score of RSB. The respondents were categorized in 'low risk group' if they had the total RSB score of $\leq 2$, and in 'high risk group' if the total RSB score was $<2$. In bivariate analyses, Chi-square test or Fisher's exact test was used as appropriate for categorical variables, and t-test was used for continuous variables to assess bivariate association between socio-demographic characteristics and levels of RSB. Multivariate logistic regression models were then constructed to detect the association between all expected risk factors and levels of RSB controlling for the effects of potential confounders. All variables were entered simultaneously in the models if they were found to have significant association with levels of RSB at a level of $p<0.05$ in bivariate analyses. SPSS version 20.0 (IBM 
Corporation, New York, NY, USA) was used for all statistical analyses.

\subsection{Ethical Statement}

This study was approved by the National Ethics Committee for Health Research, the Ministry of Health, Cambodia (Ref. no. 133 NECHR). Participation in this study was voluntary, and an informed consent was obtained from each study participant before the interview. Moreover, the study participants had an opportunity to refuse or to discontinue participation at any time. Privacy was strictly protected by conducting the interviews in a private place, and we ensured confidentiality by removing all personal identifiers from the survey questionnaires.

\section{Results}

\subsection{Characteristics of Participants}

Table 1. Socioeconomic characteristics, health risk behavior, HIV testing, and HIV education among unmarried young people recruited from hotpots in Cambodia
Table 1 shows socio-demographic characteristics, health risk behavior, HIV testing history, and HIV education of the respondents. In total, 1,204 boys and 1,166 girls were included in this study with similar mean ages (19.3 years \pm 2.9 and $19.1 \pm 2.9$, respectively). Education levels were also similar in boys and girls with more than half had completed $\geq 9$ years of formal education, but less than half were currently in school. Regarding living situations, boys were more likely to be currently living with their parents (75.7\% vs. 52.8\%), but the proportion of respondents who had both parents alive was similar (82.5\% vs. $81.3 \%$ ). More than half of boys (56.3\%) and girls (55.2\%) reported being currently unemployed, which also included being a student. It is worth-noting that $36.6 \%$ of girls reported their current job in 'other' category, which included mostly jobs in entertainment establishments such as bars, karaoke parlors, massage parlors, nightclubs or discotheques, beer gardens, restaurants, etc.

\begin{tabular}{|c|c|c|}
\hline \multirow{2}{*}{ Characteristics } & Boys $(n=1,204)$ & Girls $(n=1,166)$ \\
\hline & $n(\%)$ & $n(\%)$ \\
\hline Currently living in an urban area & $754(63.2)$ & $940(81.0)$ \\
\hline Longer duration of living in the current area* & $581(48.8)$ & $578(49.7)$ \\
\hline Mean age $( \pm$ SD) & $19.3 \pm 2.9$ & $19.1 \pm 2.9$ \\
\hline Aged 20 - 24 & 885 (48.6) & $557(47.8)$ \\
\hline Completed $\geq 9$ years of formal education & $779(64.8)$ & $713(61.1)$ \\
\hline Not currently in school & $525(43.6)$ & $514(44.1)$ \\
\hline Currently living with parents & $912(75.7)$ & 615 (52.8) \\
\hline \multicolumn{3}{|l|}{ Current employment } \\
\hline Unemployed & $677(56.3)$ & $642(55.2)$ \\
\hline Self-employed business & $68(5.7)$ & $28(2.4)$ \\
\hline Farmer/non-skilled laborer & $347(28.8)$ & $67(5.8)$ \\
\hline Other $^{\dagger}$ & $111(9.2)$ & $425(36.6)$ \\
\hline Having both parents alive & $992(82.5)$ & $946(81.3)$ \\
\hline Father is employed & $1180(98.0)$ & $1122(96.3)$ \\
\hline Mother is employed & $879(73.0)$ & $932(80.0)$ \\
\hline Current alcohol drinkers & $1058(87.9)$ & 799 (68.5) \\
\hline Current heavy alcohol drinkers & $20(1.6)$ & $142(17.8)$ \\
\hline Current illicit drug users & $176(14.6)$ & $37(3.2)$ \\
\hline Current injecting drug users & $1(0.1)$ & $6(0.5)$ \\
\hline Having been tested for HIV & $178(14.8)$ & $202(17.4)$ \\
\hline \multicolumn{3}{|l|}{ Place of the most recent HIV test } \\
\hline Private facility & $51(28.7)$ & $49(24.0)$ \\
\hline Public facility & $85(47.8)$ & 81 (39.7) \\
\hline NGO facility & $37(20.8)$ & $57(27.9)$ \\
\hline Other & $5(2.8)$ & $17(8.3)$ \\
\hline Received the result of the most recent HIV test & $173(97.7)$ & $193(95.1)$ \\
\hline Received any form of HIV education in past 3 months & $969(80.6)$ & $774(66.6)$ \\
\hline \multicolumn{3}{|c|}{ Source of HIV education obtained in the past 3 months } \\
\hline Television & $723(60.1)$ & 459 (39.5) \\
\hline Radio & $451(37.5)$ & $243(20.9)$ \\
\hline Newspaper & $92(7.7)$ & $35(3.0)$ \\
\hline Billboard & $251(20.9)$ & 132 (11.3) \\
\hline Lectures/trainings/workshops & $216(18.0)$ & $205(17.6)$ \\
\hline Health facilities & $56(4.7)$ & $36(3.1)$ \\
\hline School & $262(21.8)$ & 252 (21.7) \\
\hline Friends/family & 239 (19.9) & 198 (17.1) \\
\hline Other & 49 (3.9) & $3(0.3)$ \\
\hline
\end{tabular}

Abbreviations: NGO, non-governmental organization; SD, standard deviation.

${ }^{*}$ Median duration of living in the current area (13 years for boys and 3 years for girls) was used to divide respondents into two groups.

${ }^{\dagger}$ Other included working in entertainment establishments such as bars, night clubs, karaoke parlors, massage parlors, restaurants, etc.

Regarding health risk behavior, $87.9 \%$ of boys and $68.5 \%$ of girls reported drinking at least a full glass of alcohol in the past three months, and $1.7 \%$ of boys and $17.8 \%$ of girls perceived themselves as heavy drinkers. For other substance use, $14.6 \%$ of boys and $3.2 \%$ of girls reported using illicit drugs in the past three months, but only $0.1 \%$ of boys and $0.5 \%$ of girls reported injecting drugs in the past three months. When asked about HIV testing, $14.8 \%$ of boys and $17.4 \%$ of girls reported having been tested for HIV at least once in their lifetime. Regarding HIV-related information, $80.6 \%$ of boys and $66.6 \%$ of girls reported receiving some form of HIV education in the past three months. 


\subsection{Sexual Behavior}

Comparisons of sexual behavior among boys and girls are shown in Table 2. Compared to girls, boys were significantly more likely to have sexual intercourse in the past three months $(\mathrm{OR}=2.6,95 \% \mathrm{CI}=2.2-3.2)$ but significantly less likely to have their first sexual intercourse before the age of $18(\mathrm{OR}=1.9,95 \% \mathrm{CI}=1.3$ 2.7). Boys were also significantly more likely to have two or more sex partners in the past three months $(\mathrm{OR}=1.4$, 95\% CI= 1.1-2.0) but significantly less likely to have sexual intercourse in change for money or gifts in the past three months $(\mathrm{OR}=12.4,95 \% \mathrm{CI}=8.2-18.9)$. The majority of boys (85.5\%) reported buying sex in the past three months. The rates of consistent condom use with commercial partners were high and not significantly different in boys and girls. However, boys were significantly more likely to report always using condom with unpaid regular partners in the past three months than girls $(\mathrm{OR}=11.8,95 \% \mathrm{CI}=5.3-26.7)$.

Among sexually active girls $(n=215), 43.5 \%$ reported having been pregnant at least once in their lifetime and of them, 42.4\% reported having induced abortion as a result of their most recent pregnancy. Among girls who had experienced abortion, only $11.1 \%$ received the most recent abortion services at a public health facility, while $46.7 \%$ sought the services at a private health facility, and the remaining 42.2\% received the abortion services from other unskilled providers such as traditional birth attendants, traditional healers, or pharmacies.

Table 2. Risky sexual behavior among unmarried boys $(n=1,204)$ and girls $(n=1,166)$ recruited from hotspots in Cambodia

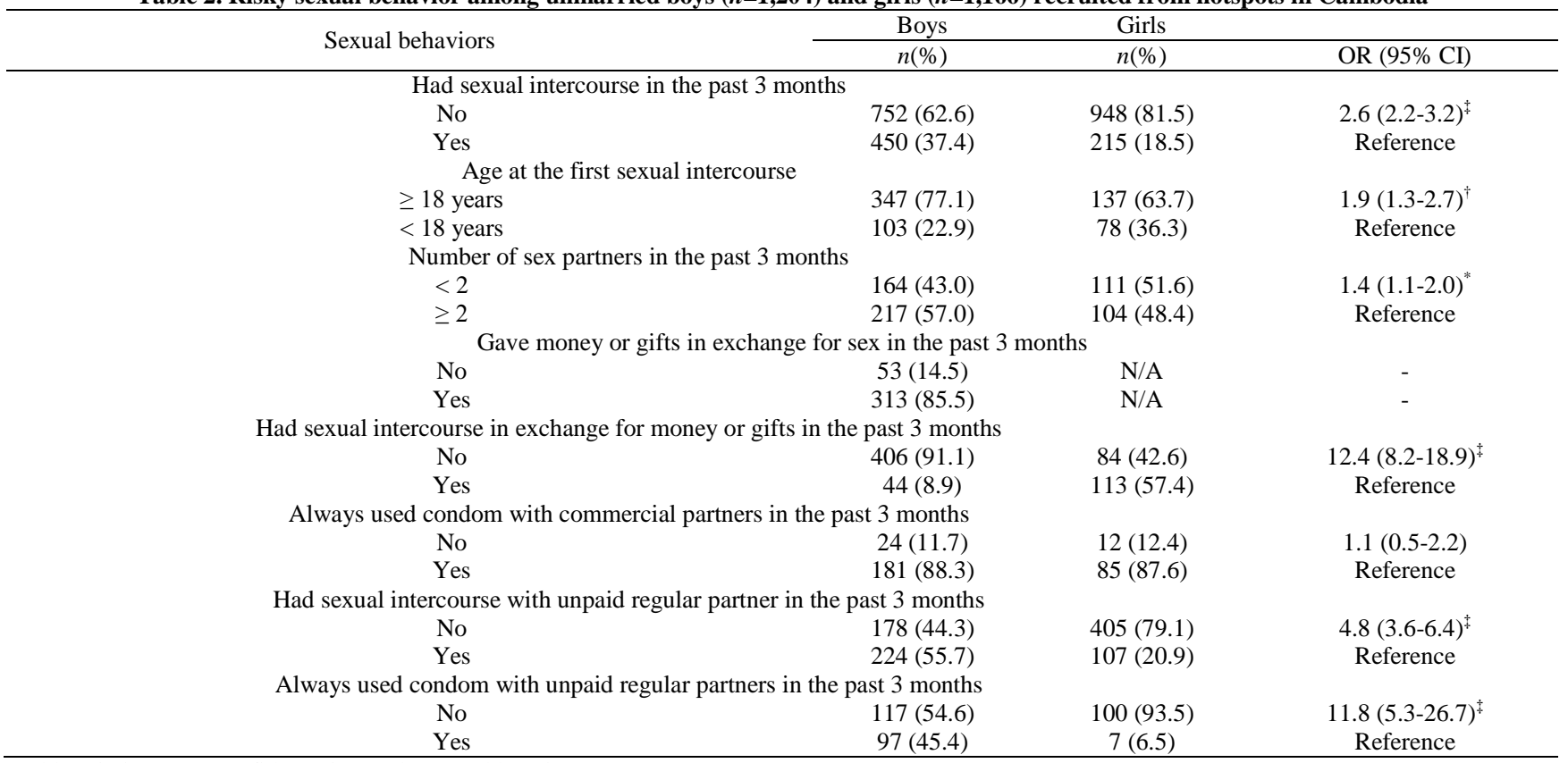

Abbreviations: CI, confidence interval; OR, odds ratio.

Notes: N/A, data were not collected from girls; ${ }^{*} \mathrm{p}$-value $<0.05$; ${ }^{\dagger}$-value $<0.01 ;{ }^{\ddagger} \mathrm{p}$-value $<0.001$.

Table 3. Comparisons of sexual behavior among boys and girls in the age groups of 10-19 and 20-24 recruited from hotspots in Cambodia

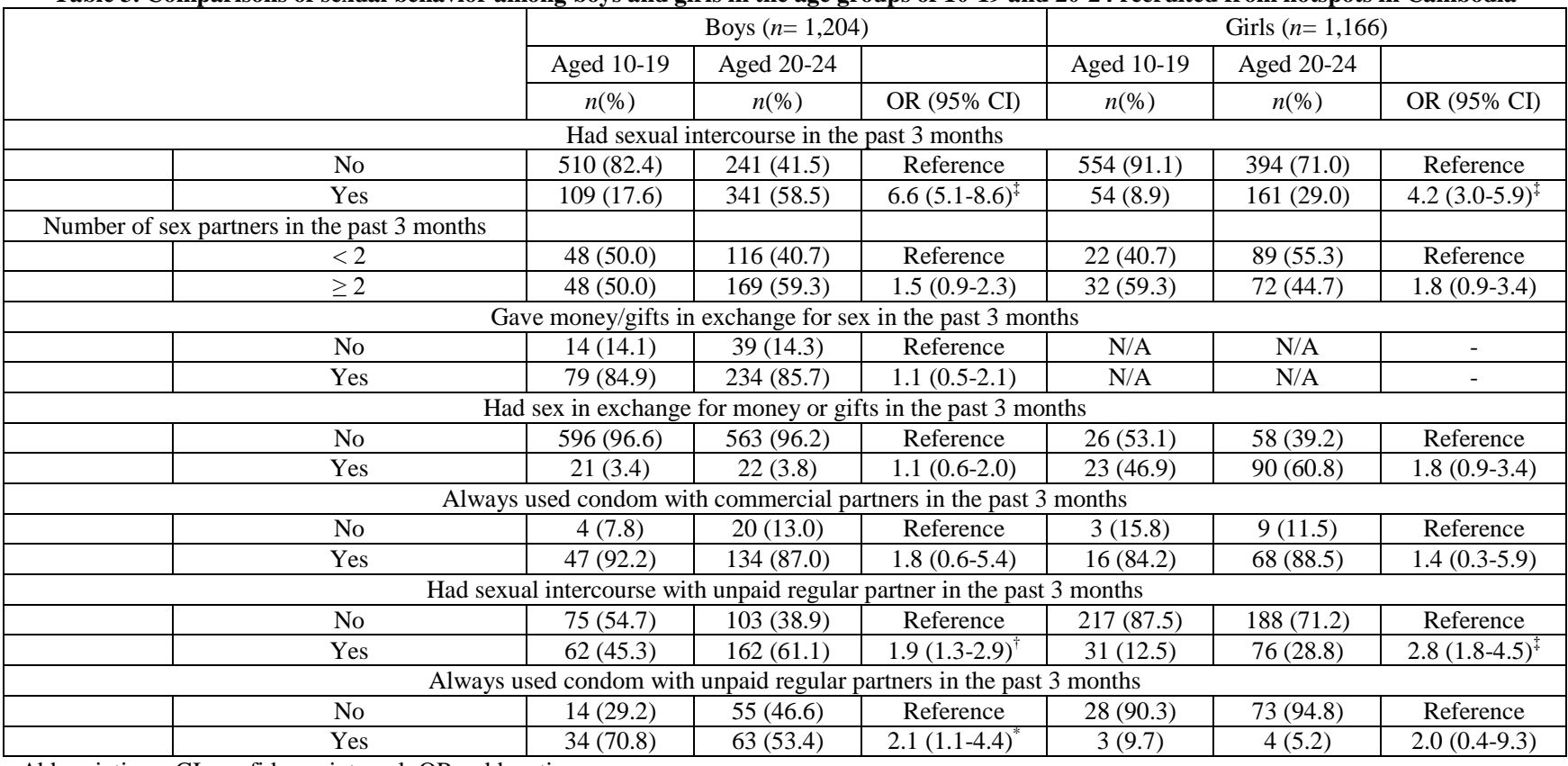

Abbreviations: CI, confidence interval; OR, odds ratio.

Notes: N/A, data were not collected from girls; ${ }^{*}$-value $<0.05 ;{ }^{\dagger}$ p-value $<0.01 ;{ }^{\ddagger}$ p-value $<0.001$. 
Table 3 shows comparisons of selected sexual behavior among boys and girls in the age groups of 10-19 and 2024. Among boys, respondents in the age group of 20-24 were significantly more likely to be sexually active in the past three months $(\mathrm{OR}=6.6,95 \% \mathrm{CI}=5.1-8.6)$ and significantly less likely to report always using condom with unpaid regular partners in the past three months $(\mathrm{OR}=2.1,95 \% \mathrm{CI}=1.1-4.4)$. Similarly, girls in the age group of 20-24 were significantly more likely to be sexually active in the past three months $(\mathrm{OR}=4.2,95 \%$ $\mathrm{CI}=3.0-5.9$ ) compared to girls in the age group of 10-19.

\subsection{Bivariate Analysis Results}

As shown in Table 4, among boys, high levels of RSB were significantly associated with several socio-economic characteristics such as living in an urban area $(\mathrm{OR}=2.0$, $95 \% \mathrm{CI}=1.5-2.6)$, being in the age group of 20-24 (OR= 5.0, 95\% CI= 3.8-6.6), having completed $\geq 9$ years of formal education $(\mathrm{OR}=1.4,95 \% \mathrm{CI}=1.1-1.8)$, being not currently in school $(\mathrm{OR}=3.3,95 \% \mathrm{CI}=2.5-4.2)$, not having both parents alive $(\mathrm{OR}=1.6,95 \% \mathrm{CI}=1.2-2.2)$, and being currently employed $(\mathrm{OR}=3.1,95 \% \mathrm{CI}=2.4-$ 4.0). High levels of RSB were also significantly associated with health risk behavior including alcohol drinking $(\mathrm{OR}=25.3,95 \% \mathrm{CI}=8.0-80.0)$, being a heavy alcohol drinker $(\mathrm{OR}=4.4,95 \% \mathrm{CI}=3.4-5.7)$, illicit drug use(OR= 5.2, 95\% $\mathrm{CI}=3.7-7.3)$, and HIV testing history $(\mathrm{OR}=3.8,95 \% \mathrm{CI}=2.7-5.2)$.

Table 4. Results of bivariate analyses of the relationship between socio-demographic and behavioral factors with levels of RSB among unmarried young people recruited from hotspots in Cambodia

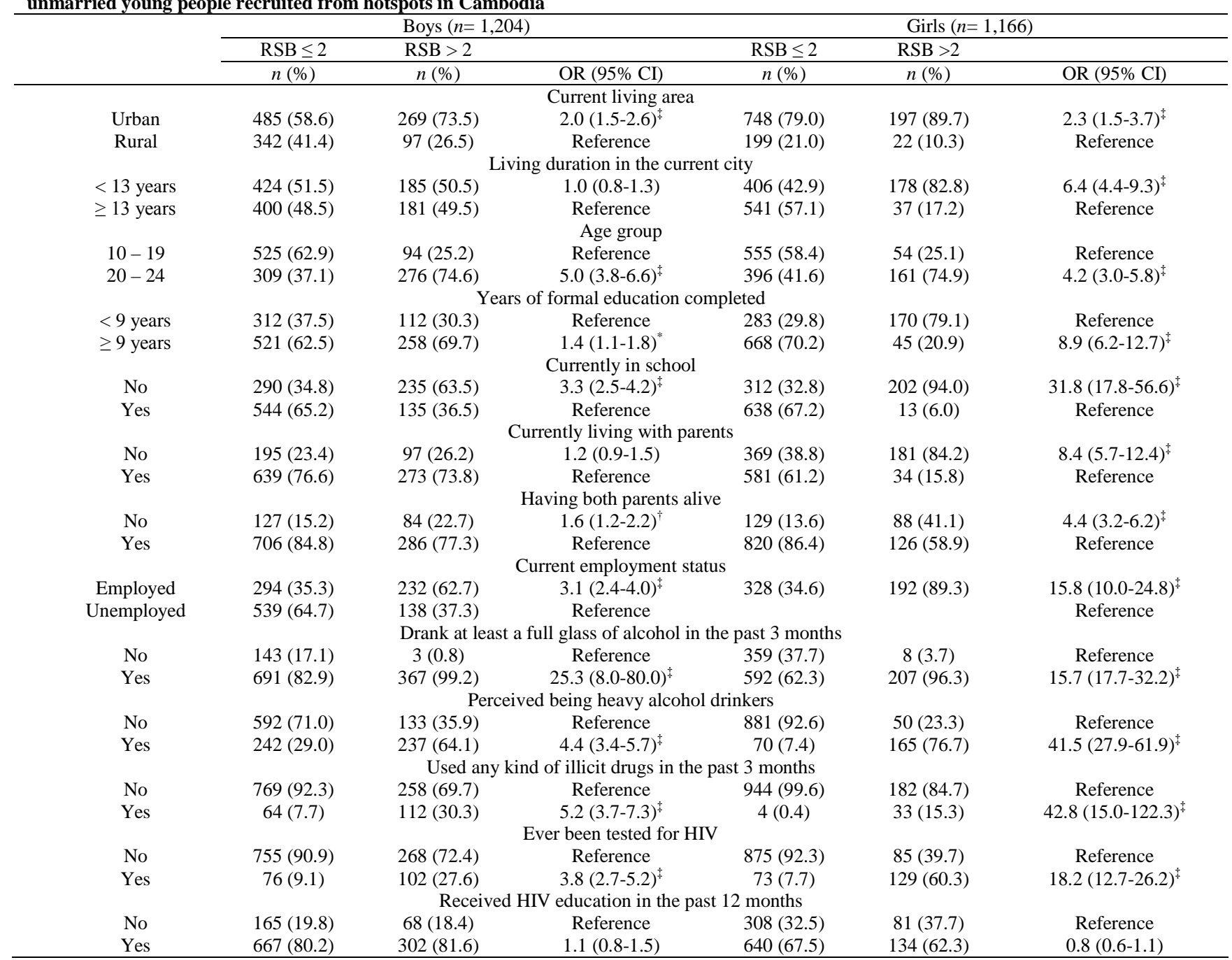

Abbreviations: CI, confidence interval; OR, odds ratio; RSB, risky sexual behavior.

Notes: N/A, data were not collected from girls; ${ }^{*} \mathrm{p}$-value $<0.05 ;{ }^{\dagger} \mathrm{p}$-value $<0.01 ;{ }^{\ddagger} \mathrm{p}$-value $<0.001$.

Among girls, high levels of RSB were significantly associated with living in an urban area $(\mathrm{OR}=2.3,95 \%$ $\mathrm{CI}=1.5-3.7)$, living in the current city for a shorter period $(\mathrm{OR}=6.4,95 \% \mathrm{CI}=4.4-9.3)$, being in the age group of 20 $24(\mathrm{OR}=4.2,95 \% \mathrm{CI}=3.0-5.8)$, being not currently in school $(\mathrm{OR}=31.8,95 \% \mathrm{CI}=17.8-56.6)$, not currently living with parents $(\mathrm{OR}=8.4,95 \% \mathrm{CI}=5.7-12.4)$, not having both parents alive $(\mathrm{OR}=4.4,95 \% \mathrm{CI}=3.2-6.2)$, being currently employed $(\mathrm{OR}=15.8,95 \% \mathrm{CI}=10.0-24.8)$, and living with unemployed father $(\mathrm{OR}=2.0,95 \% \mathrm{CI}=$ 1.1-3.9). High levels of RSB were also significantly associated with health risk behavior including alcohol drinking $(\mathrm{OR}=15.7,95 \% \mathrm{CI}=17.7-32.2)$, being heavy alcohol drinkers $(\mathrm{OR}=41.5,95 \% \mathrm{CI}=27.9-61.9)$, illicit drug use(OR=42.8, 95\% $\mathrm{CI}=15.0-122.3)$, and $\mathrm{HIV}$ testing history $(\mathrm{OR}=18.2,95 \% \mathrm{CI}=12.7-26.2)$. However, unlike boys, girls with high levels of RSB were significantly less likely to have completed $\geq 9$ years of formal education $(\mathrm{OR}=8.9,95 \% \mathrm{CI}=6.2-12.7)$.

An additional analysis among girls who had sexual intercourse in exchange for money or gifts in the past three months showed that girls who had two or more 
sexual partners in the past three months were significantly more likely to report always using condom in the past three months compared to those having less than two sexual partners in the past three months (89.9\% vs. $62.5 \%$, $\mathrm{OR}=5.3,95 \% \mathrm{CI}=1.1-6.1)$.

\subsection{Multivariate Analysis Results}

Results from the multivariate analyses are presented in Table 5. Among boys, after adjustment for other covariates in the model, high levels of RSB remained significantly associated with several socio-economic factors including living in an urban area $(\mathrm{AOR}=1.5,95 \%$ $\mathrm{CI}=1.1-2.1)$, being in the age group of $20-24(\mathrm{AOR}=2.6$,
95\% CI= 1.9-3.6), having completed $\geq 9$ years of formal education $(\mathrm{AOR}=1.7,95 \% \mathrm{CI}=1.2-2.5)$, being not currently in school $(\mathrm{AOR}=1.7,95 \% \mathrm{CI}=1.2-2.5)$, not currently living with parents $(\mathrm{AOR}=1.5,95 \% \mathrm{CI}=1.1$ $2.1)$, and being currently employed $(\mathrm{AOR}=1.6,95 \% \mathrm{CI}=$ 1.1-2.3). Regarding its relationship with health risk behavior, boys with high levels of RSB remained significantly more likely to be current alcohol drinkers $(\mathrm{AOR}=6.2,95 \% \mathrm{CI}=1.9-20.2)$, to be current heavy alcohol drinkers $(\mathrm{AOR}=2.1,95 \% \mathrm{CI}=1.5-2.8)$, to be current illicit drug users $(\mathrm{AOR}=3.0,95 \% \mathrm{CI}=2.0-4.4)$, and to have been tested for $\mathrm{HIV}(\mathrm{AOR}=2.0,95 \% \mathrm{CI}=1.3-$ 2.9).

Table 5. Results of multivariate analyses of factors associated with levels of risky sexual behaviors among unmarried most-at-risk young people

\begin{tabular}{|c|c|c|c|c|}
\hline \multirow{2}{*}{ Factors included in the models ${ }^{*}$} & \multicolumn{2}{|c|}{ Boys $(n=1,204)$} & \multicolumn{2}{|c|}{ Girls $(n=1,166)$} \\
\hline & $\mathrm{AOR}^{\dagger}(95 \% \mathrm{CI})$ & $p$-value & $\mathrm{AOR}^{\dagger}(95 \% \mathrm{CI})$ & $p$-value \\
\hline Current living area & & 0.009 & & 0.69 \\
\hline Urban & $1.5(1.1-2.1)$ & & $0.9(0.4-1.8)$ & \\
\hline Rural & Reference & & Reference & \\
\hline Age groups & & $<0.001$ & & 0.03 \\
\hline $10-19$ & Reference & & Reference & \\
\hline $19-20$ & $2.6(1.9-3.6)$ & & $1.8(1.1-2.9)$ & \\
\hline Years of formal education completed & & 0.005 & & 0.17 \\
\hline$\geq 9$ years & $1.7(1.2-2.5)$ & & $1.5(0.8-2.8)$ & \\
\hline$<9$ years & Reference & & Reference & \\
\hline Currently in school & & 0.008 & & 0.001 \\
\hline No & $1.7(1.2-2.5)$ & & $3.9(1.7-9.1)$ & \\
\hline Yes & Reference & & Reference & \\
\hline Currently living with parents & & 0.03 & & 0.23 \\
\hline No & $1.5(1.1-2.1)$ & & $1.5(0.8-2.9)$ & \\
\hline Yes & Reference & & Reference & \\
\hline Having both parents alive & & 0.26 & & 0.02 \\
\hline No & $1.3(0.9-1.9)$ & & $1.8(1.1-3.1)$ & \\
\hline Yes & Reference & & Reference & \\
\hline Currently employed & & 0.01 & & 0.93 \\
\hline No & Reference & & Reference & \\
\hline Yes & $1.6(1.1-2.3)$ & & $1.0(0.5-2.1)$ & \\
\hline Duration of living in current city & & 0.43 & & 0.42 \\
\hline$\geq 3$ years & Reference & & Reference & \\
\hline$<3$ years & $0.9(0.6-1.2)$ & & $0.8(0.4-1.5)$ & \\
\hline Living with unemployed father & & 0.81 & & 0.34 \\
\hline No & Reference & & Reference & \\
\hline Yes & $0.9(0.3-2.5)$ & & $0.6(0.2-1.8)$ & \\
\hline Being current alcohol drinkers & & 0.003 & & 0.003 \\
\hline No & Reference & & Reference & \\
\hline Yes & $6.2(1.9-20.2)$ & & $3.7(1.5-8.7)$ & \\
\hline Being heavy alcohol drinkers & & $<0.001$ & & $<0.001$ \\
\hline No & Reference & & Reference & \\
\hline Yes & $2.1(1.5-2.8)$ & & $6.3(3.6-10.9)$ & \\
\hline Being current illicit drug users & & $<0.001$ & & 0.01 \\
\hline No & Reference & & Reference & \\
\hline Yes & $3.0(2.0-4.4)$ & & $5.8(1.5-22.0)$ & \\
\hline Having been tested for HIV & & 0.001 & & $<0.001$ \\
\hline No & Reference & & Reference & \\
\hline Yes & $2.0(1.3-2.9)$ & & $6.8(4.1-11.3)$ & \\
\hline
\end{tabular}

Abbreviations: AOR, adjusted odds ratio; CI, confidence interval.

${ }^{*}$ All variables significantly associated with the levels of risky sexual behavior $(\mathrm{p}<0.05)$ in bivariate analyses were included in the multivariate logistic regression models.

${ }^{\dagger}$ The analyses were adjusted for all other covariates simultaneously included in the models.

In the model for girls, high levels of RSB remained significantly associated with being in the age group of 20$24(\mathrm{AOR}=1.8,95 \% \mathrm{CI}=1.1-2.9)$, being not currently in school (AOR= 3.9, 95\% CI= 1.7-9.1), and not having both parents alive $(\mathrm{AOR}=1.8,95 \% \mathrm{CI}=1.1-3.1)$. Similar to boys, girls with high levels of RSB remained significantly more likely to becurrent alcohol drinkers $(\mathrm{AOR}=3.7,95 \%$ $\mathrm{CI}=1.5-8.7)$, to be current heavy alcohol drinkers $(\mathrm{AOR}=$ 6.3, 95\% CI= 3.6-10.9), to be current illicit drug users $(\mathrm{AOR}=5.8,95 \% \mathrm{CI}=1.5-22.0)$, and to have been tested for HIV (AOR= 6.8, 95\% CI= 4.1-11.3).

\section{Discussion}

Findings from this study indicate the high prevalence of RSB and highlight several related socio-economic and health risk behavior factors among unmarried young people recruited from hotspots in Cambodia. Approximately half of the sexually active respondents had two or more sexual partners, and more than half had been involved in commercial sexual activities in the past three months. Although the majority of the respondents reported always using condom with commercial sex partners, the 
prevalence rates of reported consistent condom use with unpaid regular partners were very low, particularly among girls. Such behavior may expose these young people to increased risks of HIV and STIs as well as other health and socio-cultural issues such as unwanted pregnancy and induced abortion, which were found to be common among this key population. Furthermore, we also found that access to safe abortion was also limited among girls in this study.

We found that socio-demographic factors such as older age and being out of school were significantly associated with higher levels of RSB among both boys and girls. These results support findings from previous studies in different settings $(5,16,31)$. Previous studies in China and Myanmar also found that out-of-school youths had limited opportunity to receive sexual reproductive health information [5,32]. This finding highlights the lack of solutions on providing sexual reproductive health education to this vulnerable group in recent education programs, even though the importance of schooling status for sexual reproductive health education has been internationally recognized and addressed [5].

It is worth-noting that boys and girls with high levels of RSB were significantly more likely to have been tested for HIV. However, due to the small proportion of respondents who had not received the result of HIV test, we could not further analyze to see whether levels of RSB were different among boys and girls who knew the result of their most recent test compared to those who did not know it. A meta-analysis of the short- and long-term outcomes of HIV prevention interventions found that knowing one's HIV status was strongly associated with lower RSB that may support the roles of post-test counseling in changing sexual behavior of the testers [33]. However, our finding may simply indicate that people who had been involved in RSB may be more concerned about their HIV status and in turn, more likely to get tested. Future study should explore the roles of pre- and post-test counseling in changing sexual behavior among these most-at-risk young people in Cambodia.

The finding of the association between substance use and RSB extends the widespread evidence that substance use and RSB tend to co-occur among young people [22,34]. Similar findings have also been reported in our previous study among adolescent students in Cambodia [7]. In terms of specific RSB, some studies have linked substance use to higher number of sexual partners and less consistent condom use [35,36], whereas other studies have failed to find such an association [37]. Among South African youth, the use of various substances was associated with having ever had sexual intercourse but not associated with the failure to use condom in the last sexual intercourse [38].

The most frequently cited explanation for the link between substance use and RSB is "sensation-seeking behavior," which is defined as a disposition characterized by the tendency to pursue novel, exciting, and optimal levels of stimulation [39]. Another possible explanation for this co-variation is that intoxication with substances, such as alcohol or drugs, may have disorganizing effects on cognitive functions leading to poor decision-making on involvement with RSB [40,41]. In Cambodia, visits to sex workers after drinking parties are a social activity involving male friends [42], and this might also explain the relation between substance use and RSB among unmarried young people in this study.

A cross tabulation was conducted to see if there was a trend between number of clients a woman was sexually active with and levels of consistent condom use. We found that girls who reported having two or more sex partners in the past three months were more likely to report always using condom compared to those who reported having less than two sex partners. Similar finding was also reported in a previous study in South Africa [43], where consistent condom users had three times the odds of having had only one sexual partner in the past year compared to inconsistent users. This finding may indicate that girls who have fewer clients are more likely to have the same clients and form a closer relationship with the clients than girls who had more clients. As a result, both girls and their clients could feel they are less at risk for transmission of HIV and STIs from one another.

This study has several limitations. First, the crosssectional nature prohibited us from concluding on a causal relationship between the risk factors and RSB. Second, there might be inherent biases and the potential for both underreporting and over-reporting as a result of the use of questionnaire survey. Given the cultural norms governing sexual behavior in Cambodian society, sexual behavior tends to be over-reported by boys and under-reported by girls. However, this bias has been minimized by using interviewers who were similar to respondents in terms of age group and gender with intensive training and support. The final limitation concerns the representativeness of the study population. Young people targeted in this study were at-risk populations; therefore, they may not represent young people in Cambodia as a whole. Furthermore, this survey included only hotspots in the capital city and seven provinces purposefully selected to include a higher likelihood of having youths who are at risks; therefore, the findings are not nationally representative even within the most-at-risk populations. However, given that probability sampling was used coupled with careful mapping of hotspots using time-location method, the samples are representative of the key populations within the selected city and provinces.

\section{Conclusions}

Unmarried young people in this study are at remarkably high risk of sexual reproductive health problems such as HIV, STIs, unwanted pregnancy, and unsafe abortion. Their RSB are associated with a number of socioeconomic factors and health risk behavior such as alcohol and substance use. These findings suggest the need for research and prevention programs for these young people. Further studies are needed to understand who are at the greatest risks, and where the real hotspots are among these key populations. HIV prevention programs should be developed to change individual behavior under the guidance of health promotion theoretical frameworks. One such framework is the information-motivation-behavioral skills (IMB) model that has been tested in various at-risk groups in different countries $[44,45,46,47]$.

\section{Acknowledgments}


We gratefully acknowledge the support extended by Ministry of Education, Youth, and Sports; FHI; KHANA; PSI; UNAIDS; UNESCO; UNFPA; UNICEF; and WHO for providing financial and technical support for this study. We would like to express our appreciation and gratitude to all participants, research team members, and local coordinators whose dedicated efforts ensured the quality and timeliness of the survey.

\section{Statement of Competing Interests}

The authors have no competing interests.

\section{References}

[1] UNAIDS, Joint United Nations Programme on HIV/AIDS and World Health Organization. 2009 AIDS epidemic update. UNAIDS/WHO, Geneva, Switzerland, Nov. 2009.

[2] UNAIDS, Joint United Nations Programme on HIV/AIDS. Global report: UNAIDS report on the global AIDS epidemic 2013. UNAIDS, Geneva, Switzerland, Nov. 2013.

[3] Ahmadian, M., Hamsan, H.H., Abdullah, H., Samah, A.A. and Noor, A.M., "Risky sexual behavior among rural female adolescents in Malaysia: A limited role of protective factors," Global Journal of Health Sciences, 6 (3). 165-174. Mar. 2014.

[4] Sychareun, V., Phengsavanh, A., Hansana, V., Chaleunvong, K., Kounnavong, S., Sawhney, M. and Durham, J., "Predictors of premarital sexual activity among unmarried youth in Vientiane, Lao PDR: the role of parent-youth interactions and peer influence," Global Public Health, 8 (8). 958-975. Sep. 2013.

[5] Thin Zaw, P.P., Liabsuetrakul, T., McNeil, E. and Htay, T.T., "Gender differences in exposure to SRH information and risky sexual debut among poor Myanmar youths,” BMC Public Health, 5.1122. Dec. 2013.

[6] Sychareun, V., Thomsen, S., Chaleunvong, K. and Faxelid, E., "Risk perceptions of STIs/HIV and sexual risk behaviours among sexually experienced adolescents in the northern part of Lao PDR,” BMC Public Health, 13. 1126. Dec. 2013.

[7] Yi, S., Poudel, K.C., Yasuoka, J., Palmer, P.H., Yi, S. and Jimba, M., "Role of risk and protective factors for risky sexual behaviors among high school students in Cambodia," BMC Public Health, 10. 477. Aug. 2010.

[8] National Institute of Statistics, Directorate General for Health, and ORC Macro. Cambodia Demographic and Health Survey 2010. Phnom Penh, Cambodia and Calverton, MD, USA. National Institute of Statistics, Directorate General for Health, and ORC Macro, Phnom Penh, Cambodia, Sep. 2011.

[9] Ministry of Education, Youth, \& Sports. Most at risk young people survey in Cambodia, 2010. Ministry of Education, Youth, \& Sports, Phnom Penh, Cambodia, Jan. 2010.

[10] Cuffee, J.J., Hallfors, D.D. and Waller, M.W., "Racial and gender differences in adolescent sexual attitudes and longitudinal associations with coital debut," Journal of Adolescent Health, 41 (1). 19-26. Jul. 2007.

[11] Guo, W., Wu, Z., Qiu, Y., Chen, G. and Zheng, X., "The timing of sexual debut among Chinese youth," International Perspective on Sexual and Reproductive Health 38 (4). 196-204. Dec. 2012.

[12] Hindin, M.J. and Fatusi, A.O., "Adolescent sexual and reproductive health in developing countries: an overview of trends and interventions," International Perspective on Sexual and Reproductive Health, 35 (2). 58-62. Jun. 2009.

[13] Oljira, L., Berhane, Y. and Worku, A., "Pre-marital sexual debut and its associated factors among in-school adolescents in Eastern Ethiopia,” BMC Public Health, 12. 375. May 2010.

[14] Kenney, J.W., Reinholtz, C. and Angelini P.J., "Ethnic differences in childhood and adolescent sexual abuse and teenage pregnancy," Journal Adolescent Health, 21 (1). 3-10. Jul. 1997.

[15] Van Decraen, E., Michielsen, K., Herbots, S., Van Rossem, R. and Temmerman, M., "Sexual coercion among in-school adolescents in Rwanda: prevalence and correlates of victimization and normative acceptance," African Journal Reproduction Health 16 (3). 140-154. Sep. 2012.
[16] Ministry of Education, Youth, \& Sports. Cambodia National Youth Risk behavior survey, 2004. Ministry of Education, Youth, \& Sports, Phnom Penh, Cambodia, Dec. 2004.

[17] Tang, J., Gao, X., Yu, Y., Ahmed, N.I., Zhu, H., Wang, J. and Du, Y., "Sexual knowledge, attitudes and behaviors among unmarried migrant female workers in China: a comparative analysis," BMC Public Health, 11. 917. Dec. 2011.

[18] Liu, Z., Zhu, M., Dib, H.H., Li, Z., Shi, S. and Wang, Z., "RH knowledge and service utilization among unmarried rural-to-urban migrants in three major cities, China," BMC Public Health, 11. 74. Feb. 2011.

[19] Tu, X., Cui, N., Lou, C. and Gao, E., "Do family-planning workers in China support provision of sexual and reproductive health services to unmarried young people?,” Bulletin of the World Health Organization, 82 (2). 274-280. Apr. 2004.

[20] Jones, C. and Long, D., "Cambodia: HIV TRaC Study Evaluating Condom Use with Sweethearts among High Risk Urban Men from four cities in Cambodia.” Population Services International, Phnom Penh, Cambodia, Feb. 2010.

[21] Cui, N., Tang, G., Li, M., Tian, A., Xie, L. and Lu, S.Y., "Survey of needs for reproductive health of unmarried adolescents in Chengdu," Chinese Journal of Family Planning, 8 (2): 208-212. Feb. 2000.

[22] Palen, L.A., Edward, A.S., Flisher, A.J., Caldwell, L.L. and Mpofu, E., "Substance use and sexual risk behavior among South African eighth grade students," Journal of Adolescent Health, 39 (5). 761-763. Nov. 2006.

[23] Carter, M., McGee, R., Taylor, B. and Williams,S., "Health outcomes in adolescence: Associations with family, friends, and school engagement," Journal of Adolescence, 30 (1). 51-62. Feb. 2007.

[24] Le, T.N. and Kato, T., "The role of peer and culture in risky sexual behavior for Cambodian and Lao/Mien adolescents," Journal of Adolescent Health, 38 (3). 288-296. Mar. 2006.

[25] Wight, D., Williamson, L. and Henderson, M., "Parental influences on young people's sexual behavior: A longitudinal analysis,” Journal of Adolescence, 29 (4). 473-473. Aug. 2006.

[26] Borawski, E.A., Ievers-Landis, C.E., Lovegreen, L.D. and Trapl, E.S., "Parental monitoring, negotiated unsupervised time, and parental trust: The role of parenting practices in adolescent health risk behaviors," Journal of Adolescent Health, 33 (2). 60-70. Aug. 2003.

[27] Fulkerson, J.A., Story, M., Mellin, A., Leffert, N., NeumarkSztainer, D. and French, S.A., "Family dinner meal frequency and adolescent development: Relationship with development assets and high-risk behaviors," Journal of Adolescent Health, 39 (3). 337-337. Sep. 2006.

[28] Peres, C.A., Rutherford, G., Borges,G., Galano, E., Hudes, E.S. and Hearst, N., "Family structure and adolescent sexual behavior in a poor area of Sao Paulo, Brazil," Journal of Adolescent Health, 42 (2). 177-183. Feb. 2008.

[29] National Institute of Statistics, Directorate General for Health, and ORC Macro. Cambodia Demographic and Health Survey 2005. Phnom Penh, Cambodia and Calverton, Maryland, USA: National Institute of Statistics and ORC Macro, Dec. 2006.

[30] Eaton, D.K., Kann, L., Kinchen, S., Shanklin, S., Ross, J., Hawkins, J., Harris, W.A., Lowry, R., McManus, T., Chyen, D., Lim, C., Whittle, L., Brener, N.D. and Wechsler, H., Youth Risk Behavior Surveillance-United Sates, 2009. Morbidity and Mortality Weekly Report, 59 (SS05). 1-142. Jun. 2010.

[31] Hutchinson, M.K., Jemmott, J.B., Jemmott, L.S., Braverman, P. and Fong, G.T., "The role of mother-daughter sexual risk communication in reducing sexual risk behaviors among urban adolescent females: a prospective study," Journal of Adolescent Health, 33 (2). 98-107. Aug. 2003.

[32] Wang, B., Li, X., Stanton, B., Kamali, V., Naar-King, S., Shah, I. and Thomas, R., "Sexual attitudes, pattern of communication, and sexual behavior among unmarried out-of-school youth in China," BMC Pubic Health, 7. 189. Jul. 2007.

[33] Earl, A. and Albarracin, D., "Nature, decay, and spiraling of the effects of fear-inducing arguments and HIV counseling and testing: A meta-analysis of the short-and long-term outcomes of HIV prevention interventions,” Health Psychology, 26 (4). 496-506. Jul. 2007.

[34] Simbayi, L.C., Kalichman, S.C., Jooste, D., Mathiti. V., Cain, D. and Cherry, C., "Alcohol use and sexual risks for HIV infection among men and women receiving sexually transmitted infection 
services in Cape Town, South Africa," Journal of Studies on Alcohol, 65 (4). 434-442. Jul. 2004.

[35] Lowery, R., Galuska, D.A., Fulton, J.E., Wechsler, H., Kann, L. and Collins. J.L., "Physical activity, food choice, and weight management goals and practices among U.S. college students," American Journal of Preventive Medicine, 18 (1). 18-27. Jan. 2000.

[36] Tapert, S.F., Aarons, G.A., Sedlar, G.R. and Brown, S.A., "Adolescent substance use and sexual risk-taking behavior," Journal of Adolescent Health, 28 (3). 181-189. Mar. 2001.

[37] Morrison, D.M., Gillmore, M.R., Hoppe, M.J., Gaylord, J., Leigh, B.C., Rainey, D., "Adolescent drinking and sex: findings from a daily diary study," Perspectiveson Sexual and Reproductive Health, 35 (4).162-168. Jul-Aug. 2003.

[38] Flisher, A.J. and Chalton, D.O., "Adolescent contraceptive nonuse and co-variation among risk behaviors," Journal Adolescent Health, 28 (3). 235-241. Mar. 2001.

[39] Zuckerman, M., Eysenck, S. and Eysenck, H.J., "Sensation seeking in England and America: Cross-cultural, age, and sex comparisons," Journal of Consulting and Clinical Psychology, 46 (1). 139-149. Feb. 1978.

[40] Baskin-Sommers, A. and Sommers, D.S.W., "The co-occurrence of substance use and high-risk behaviors," Journal of Adolescent Health, 38 (5). 609-611. May 2006.

[41] Bell, D.C., Trevino, R.A., Atkinson, J.S. and Carlson, J.W., "Motivations for condom use and non-use," Clinical Laboratory Science, 16 (1). 20-33. Jan. 2003.
[42] Douthwaite, M.R. and Sareoun, L., "Sexual behavior and condom use among unmarried young men in Cambodia," AIDS Care, 18 (5). 505-513. Jul. 2006.

[43] JamaShai, N., Jewkes, R., Levin, J., Dunkle, K. and Nduna, M., "Factors associated with consistent condom use among rural young women in South Africa," AIDS Care, 22 (11). 1379-1385. Nov. 2010.

[44] Cai, Y., Ye, X., Shi,R., Xu, G., Shen, L., Ren, J. and Huang, H., "Predictors of consistent condom use based on the InformationMotivation-Behavior Skill (IMB) model among senior high school students in three coastal cities in China," BMC Infectious Diseases, 13. 262. Jun. 2013.

[45] Fisher, C.M., "Are information, motivation, and behavioral skills linked with HIV-related sexual risk among young men who have sex with men?," Journal of HIV/AIDS and Social Services, 10 (1). 5-21. Jan. 2011.

[46] Scott-Sheldon, L.A., Carey, M.P., Vanable, P.A., Senn, T.E., Coury-Doniger, P. and Urban, M.A., "Predicting condom use among STD clinic clients using the Information-Motivationbehavioral Skills (IMB) model," Journal of Health Psychology, 15 (7) 1093-1102. Oct. 2010.

[47] Walsh, J.L., Senn, T.E., Scott-Sheldon, L.A., Vanable, P.A. and Carey, M.P., "Predicting condom use using the InformationMotivation-Behavioral Skills (IMB) model: a multivariate latent growth curve analysis," Annals of Behavioral Medicine, 42 (2). 235-244. Oct. 2011. 